\title{
DISPUTAS ELECTORALES: ACTORES \\ Y PRÁCTICAS POLÍTICAS \\ (MENDOZA, SEGUNDA MITAD \\ DEL SIGLO XIX) ${ }^{1}$
}

\section{Electoral disputes: political actors and practices (Mendoza, second half of the 19th century)}

\author{
Eliana Fucili \\ Universidad Nacional de Cuyo, Argentina
}

\begin{abstract}
Resumen: Este trabajo tiene como objetivo analizar las estrategias y alianzas políticas desplegadas por los sectores dirigentes mendocinos durante los comicios que se practicaban en la provincia de Mendoza. Como es sabido, en esta provincia -al igual que en otros escenarios provinciales-, el juego electoral era organizado por los clubes políticos o electorales, que se encargaban de movilizar a la ciudadanía, formar la opinión pública y reclutar votos, de manera que se propiciaban canales de delegación de la soberanía desde las bases. Ahora bien, ¿cómo estaban conformadas esas asociaciones políticas en Mendoza?, ¿qué papel ocuparon las dirigencias locales en ellas?, ¿qué mecanismos utilizaron para reclutar las bases de apoyo?
\end{abstract}

Palabras clave: comicios, siglo XIX, dirigentes políticos, clubes electorales.

Abstract: The aim of this work is to analyze the political strategies and alliances deployed by the ruling groups of Mendoza during the elections held in the province of Mendoza. As is well known, the electoral game - as in other provincial scenarios - was organized by political and electoral clubs that were in charge of citizens' mobilization, shaping public opinion, and attracting votes, thus fostering channels to delegate sovereignty from the grassroots. So, how were these political associations formed in Mendoza? Which roles did local leaders play in such associations? And what mechanisms did they use to recruit their supporters?

Keywords: elections, 19th century, political leaders, electoral clubs.

1. Una versión preliminar de este trabajo fue presentada en el simposio «El funcionamiento del poder en el ámbito local. América Latina, siglos XIX-XX», organizado por el Taller de Estudios e Investigaciones Andino-Amazónicos de la Universidad de Barcelona, que se celebró en Barcelona los días 10 y 11 de diciembre de 2020. 


\section{Introducción}

Desde hace algunas décadas, la historiografía ha renovado las interpretaciones sobre la vida política iberoamericana y ha abordado desde diversas perspectivas los procesos de conformación y consolidación de las dirigencias provinciales y nacionales durante el siglo XIX. Puntualmente los estudios sobre la experiencia de Argentina han arrojado luz sobre las características de los elencos dirigentes, las dinámicas locales, la interacción entre dirigentes regionales o provinciales con la escena nacional y el papel que cumplieron los grupos políticos provinciales y territoriales en la tarea de garantizar el funcionamiento del orden político en construcción. En su conjunto, estos estudios han mostrado las tensiones y desencuentros entre poderes nacionales, provinciales y locales, y han precisado el manejo que las dirigencias tenían de cada uno de esos niveles, así como los conflictos y tensiones que tuvieron lugar entre quienes detentaban el poder (Birle, 2007; Sabato y Lettieri, 2011).

Uno de los tópicos abordados por numerosos estudios ha sido el de las prácticas electorales, las cuales, como es sabido, eran no solo necesarias para acceder a los cargos políticos, sino también fundamentales para legitimar la autoridad. En su conjunto, los trabajos han arrojado luz sobre el universo electoral atendiendo a los modos de designación y negociación de las candidaturas, los mecanismos de movilización de los votantes, los comicios, el fraude, etc. El presente artículo propone avanzar en esa línea de investigación a través del análisis de las prácticas electorales en Mendoza, una provincia ubicada en el oeste de Argentina, durante la segunda mitad del siglo XIX. ${ }^{2}$ Puntualmente interesa indagar las estrategias y alianzas políticas desplegadas por los sectores dirigentes de la provincia durante las épocas en que se debían practicar los comicios. Para ello se propone centrar la atención en el rol que cumplieron los clubes políticos - también llamados electorales - que se organizaban en la provincia para poner en marcha el juego electoral. Como es sabido, durante la segunda mitad del siglo XIX, dichas asociaciones fueron el engranaje central del juego electoral no solo en Mendoza, sino también en otros escenarios provinciales.

Atendiendo a ello se propone como hipótesis de trabajo la idea de que dichos espacios asociativos ofrecieron interesantes posibilidades a las dirigencias políticas mendocinas para establecer nuevas relaciones, realizar alianzas que les permitieran instrumentar intereses políticos y desarrollar sus carreras políticas, y tomar contacto con potenciales electores. A fin de poner a prueba esta hipótesis, interesa investigar cómo estaban conformadas esas asociaciones po-

2. De acuerdo con los datos censales - Censo Provincial de 1864 y Censos Nacionales de 1869 y 1895 -, la provincia de Mendoza atravesó, en la segunda mitad del siglo XIX, un notable crecimiento poblacional, el cual se acentuó a partir de la década de 1870 como consecuencia del incremento vegetativo e inmigratorio. Su distribución no fue uniforme en todo el territorio, ya que las características geográficas y ambientales de la provincia condicionaron el emplazamiento de asentamientos poblacionales y de establecimientos productivos que fueron ubicados, mayormente, en los márgenes de los ríos Mendoza y Tunuyán, los cuales dieron forma al llamado oasis norte, sobre el que se asentó por entonces, aproximadamente, el $80 \%$ de la población (Richard-Jorba, 1998). 
líticas en Mendoza, qué papel ocuparon las dirigencias locales en ellas y qué mecanismos utilizaron para reclutar las bases de apoyo.

Estos interrogantes han sido abordados principalmente a partir de un exhaustivo análisis de los periódicos El Constitucional, La Opinión y La Libertad. Ciertamente, la consulta de la prensa mendocina resultó clave para identificar, reconstruir y caracterizar los clubes electorales mendocinos atendiendo a quienes eran sus miembros, sus actividades principales, los discursos pronunciados en sus reuniones, las ideas y propuestas políticas postuladas, así como los recursos materiales que utilizaban para hacer campaña en la ciudad y en las zonas rurales, tales como mítines, edición de periódicos facciosos y banquetes. Luego de realizar un primer rastrillaje, se avanzó en la elaboración de una base de datos que reúne información sobre los miembros de los clubes con el objetivo de trazar su perfil socioprofesional y su injerencia en la vida política. Para ello se utilizaron fundamentalmente datos extraídos de los censos nacionales de 1869 y $1895^{3}$ y los Registros Oficiales de la Provincia de Mendoza. ${ }^{4}$ Los primeros brindaron información respecto a la nacionalidad, edad, profesión/oficio y alfabetización de los individuos, mientras que los segundos fueron indispensables para rastrear a quienes cumplieron funciones o cargos políticos en el aparato estatal provincial.

Con el objetivo de agilizar la exposición, el trabajo se organiza en dos apartados. El primero de ellos presenta una breve reseña de las normativas y características de los comicios en la provincia durante la segunda mitad del siglo XIX a fin de presentar un cuadro general sobre las prácticas electorales. Y el segundo expone un examen sobre el funcionamiento de los clubes electorales y examina con detenimiento dos clubes que compitieron en los comicios de 1870 , con el propósito de avanzar en la reconstrucción del entramado político desplegado en el territorio provincial.

\section{Breve caracterización de las leyes electorales mendocinas}

De acuerdo con las legislaciones vigentes, había dos modalidades de votación. Una era el voto directo, utilizado para la elección de concejales municipales y diputados provinciales, los cuales se renovaban por mitades todos los años. ${ }^{5} \mathrm{La}$ otra era el voto indirecto, que se ejercía para realizar la elección de presidente y vicepresidente, senadores nacionales y gobernador. El voto indirecto para la elección de gobernador se hacía por medio de los representantes de la Legislatura mendocina doblada en número; en cambio, los senadores se elegían por

3. Las células censales están disponibles en: www.familysearch.org.

4. Los Registros Oficiales de la Provincia de Mendoza correspondientes a los años 1852-1900 se encuentran preservados en el Archivo Histórico de la Provincia de Mendoza (en adelante, AHPM).

5. Cada distrito debía elegir los representantes de acuerdo con su volumen de población: Ciudad (7 representantes), San Martín (3), Junín (3), Guaymallén (3), San Carlos (2), La Paz (1), Maipú (3), Luján (2) y San Vicente (2), aunque los números sufrieron algunas modificaciones luego de las leyes sancionadas en 1880 y 1887 (Seghesso, 1988). 
la Legislatura provincial transformada en Asamblea. Mientras, las elecciones de presidente y vicepresidente de la nación surgían de una Junta de Electores conformada por diez electores propietarios y dos suplentes.

El sufragio era universal -es decir, no existían restricciones de instrucción o propiedad-y optativo, por lo que la apertura e inscripción del registro electoral constituía el nervio de la participación electoral (Malamud, 1995). Aquellos que querían participar en los comicios debían, en primera instancia, inscribirse en el registro electoral correspondiente a su distrito. Dichos registros eran confeccionados por vecinos y autoridades del departamento, quienes eran nombrados por el poder ejecutivo provincial y constituían un importante instrumento, ya que controlaban y, en ocasiones, manipulaban los registros electorales. ${ }^{6}$ El día de los comicios se instalaban las mesas receptoras de votos.

El voto, además de voluntario, debía ser individual y público. Cada sufragante debía expresarlo de forma verbal o escrita. Una vez concluían los comicios, se procedía al escrutinio y, posteriormente, se enviaba a la Legislatura la documentación para su conteo final. Los resultados eran remitidos al Poder Ejecutivo, que tenía un plazo de tres días para su aprobación (Seghesso, 1988: 466-477). De esta forma, estaba organizado el sistema de representación ideal que se apoyaba en un concepto de ciudadanía fundado en un perfil de votante autónomo y ajeno a los vínculos de dependencia. No obstante, tal como algunos trabajos han señalado, la representación real distaba de la representación ideal, y se dirimía en un ejercicio electoral protagonizado por actores diversos cuyo voto iba más allá de la voluntad de cada votante y se convertía en un acto colectivo, en el que los clubes electorales tenían un rol cardinal (Sabato, 1998; Bragoni, 2003). Así, en cada elección se ponían en funcionamiento estas maquinarias electorales cuyo principal objetivo era conseguir adhesiones y reeditar alianzas y vínculos territoriales, militares, de amistad y parentesco.

Un elemento central de este engranaje fueron los clubes políticos o electorales instalados en la provincia, cuyas características eran similares a las de los clubes instalados en otros escenarios provinciales. Esos espacios asociativos, que se encontraban en estrecha conexión con los partidos políticos, cumplieron un rol central no solo en la organización de los trabajos electorales en el espacio urbano y rural y en la movilización de electores, sino también en la definición de las candidaturas (Sabato, 1998; Bonaudo, 2003; Navajas, 2009; Cucchi, 2014). Tal como ha señalado Pilar González Bernaldo (1999), el rol de los clubes políticos era de gran importancia en los trabajos previos a la elección.

6. La composición de los Registros Cívicos fue modificada por distintas leyes. La ley de 1864 estableció que los registros debían conformarse por el juez de letras en la ciudad y el subdelegado en la campaña, junto con dos o más vecinos. En 1880 una nueva ley electoral los denominó Juntas Calificadoras y respetó su composición. Por su parte, la Constitución de 1894/1895 estableció que las mesas inscriptoras debían estar conformadas por un juez de paz, un municipal y un ciudadano. Todos ellos debían ser nombrados por la misma junta que designaba la mesa receptora de votos (Seghesso, 1988). 
Dado que el voto era universal y optativo, su objetivo principal era movilizar a la ciudadanía para convenir las candidaturas que debían presentarse en los comicios, con lo que se propiciaban canales de delegación de la soberanía desde las bases. Su existencia era efímera, ya que su razón de ser eran las elecciones, por lo que muchos desaparecían o simplemente no volvían a reactivar su actividad hasta los siguientes comicios. Sabato explica que, asimismo, dichas asociaciones estaban en estrecha conexión con los partidos políticos, los cuales se mantenían por encima de la lucha por las candidaturas, mientras que en su propio seno operaba el club encargado de movilizar individuos en favor de ciertos candidatos y de formar la opinión.

Durante la década de 1880, la prensa local da cuenta de una modificación en la organización de estas asociaciones políticas. Los clubes electorales que pulularon hasta entonces comenzaron a menguar y fueron, poco a poco, desplazados de la competencia facciosa. En su lugar sobrevinieron los comités (a veces también denominados clubes), que a diferencia de los clubes electorales de las décadas anteriores no tuvieron un carácter efímero y espontáneo, sino que pertenecieron al «partido", entendido este como una agrupación laxa y no institucionalizada, que reunía a los líderes y sus redes políticas (Palti, 2007; Sabato, 2014: 108). Aun así, sus actividades mantuvieron algunas similitudes con los clubes electorales: se encargaron de definir las candidaturas, de conseguir adhesiones entre los distintos sectores de la sociedad local y de obtener recursos relacionales y monetarios para difundir las listas de candidatos. Su organización puede ser entendida como un instrumento destinado a disciplinar la confrontación a través de la instauración de un «partido» que, a partir de 1880, apuntó a negociar internamente las candidaturas y a controlar los comicios para evitar la competencia abierta (Sabato et al., 2011; Sabato, 2014). Hacia el final del siglo XIX, estas estructuras sufrieron modificaciones, cuando comenzaron a organizarse partidos «permanentes», los cuales, tal como ha señalado Hirsh (2017) para la experiencia de Buenos Aires, fueron entendidos por sus mentores como mecanismos destinados a representar las diversas opiniones políticas en las que se dividía el pueblo, a velar por el bien común, a ejercer cierto control sobre el gobierno y a estimular la participación activa de los ciudadanos y el interés en los asuntos de la comunidad.

Ahora bien: ¿cómo funcionaban esas asociaciones?, ¿cuál era su estructura interna? y ¿quiénes eran sus miembros?

\section{Disputas electorales de 1870: clubes y actores políticos}

Para responder a estos interrogantes proponemos realizar un análisis comparativo entre dos clubes en pugna en las elecciones de 1870. Pero antes es preciso introducir ciertas notas respecto a la situación política mendocina. Tres años antes, en 1867, había finalizado una revolución federal que tuvo como correlato el afianzamiento del consenso liberal en Mendoza y que se tradujo en el desmadre de los rebeldes y en la implementación de una compleja maquinaria destinada a restablecer el orden político y afirmar la autoridad nacional tanto en Men- 
doza como en las demás provincias donde se propagó la insurrección. Pocos meses después del restablecimiento del orden político, aún en 1867, fueron aprobadas las elecciones que proclamaban a Nicolás A. Villanueva gobernador propietario de Mendoza. Su figura puso en escena nuevos ingredientes en las rivalidades políticas locales que ganarían vigor en los años siguientes. En efecto, hacia finales de su gobernación, que acabó en 1870, se organizó en el seno de la facción gobernante un grupo de oposición que contó con el apoyo de los elementos desplazados del escenario político luego de 1867, y cuyo objetivo principal fue articular sus fuerzas políticas para alcanzar el poder.

Esta situación se palpó especialmente en las dos contiendas electorales practicadas entre enero y septiembre de 1870. En la primera se disputaban dos cargos de diputados nacionales, mientras que en la segunda estaba en juego la gobernación de la provincia. Tal como era frecuente en la época, las asociaciones electorales y los diarios desempeñaron un papel central en las disputas políticas como portavoces y foros de discusión de quienes aspiraban al poder.

En ese clima político efervescente se iniciaron, a partir de diciembre de 1869, los trabajos electorales y se dieron a conocer los candidatos para el Congreso Nacional. Los candidatos fueron: el abogado Lucas González Pintos y el hacendado local Augusto Gil, dos personajes de larga trayectoria política. Ambos fueron apoyados por el gobierno de Nicolás A. Villanueva y su propaganda política se hizo a través de las páginas del periódico La Opinión. Dicho diario señaló que ambos hombres eran dos figuras respetables cuya trayectoria política les permitiría «representar a la provincia».?

Además, un grupo de artesanos - cuyas trayectorias públicas se vinculaban en la afiliación a la Sociedad de Socorros Mutuos de Artesanos - presentaron como candidatos a Deoclesio García y a Francisco Civit. El primero no contaba aún con una dilatada trayectoria política, únicamente había sido diputado provincial entre 1863 y 1864, y luego había ejercido algunas funciones públicas, entre ellas, la de jefe de la Policía, en 1868. En cambio, Francisco Civit (1830-1908) ya había ocupado una banca en el Congreso entre 1862 y 1866, función que abandonó para regresar a la provincia y colaborar en el gobierno de Melitón Arroyo entre 1866 y 1867.

De acuerdo con las fuentes consultadas, los trabajos electorales llevados adelante por los clubes requirieron de la movilización de eventuales apoyos, indispensables para organizar alianzas y redes dispuestas a sostener una determinada candidatura. Si bien es difícil reconstruir el tipo de vínculo que se establecía para conseguir adhesiones, cuáles fueron los beneficios o intercambios materiales y simbólicos que se otorgaban o de qué manera se realizaba el reclutamiento de las bases, algunas evidencias - cartas y solicitadas, entre otraspermiten distinguir a ciertos actores políticos capaces de utilizar recursos para

7. «Constitución Provincial». La Opinión, Mendoza, año 1, núm. 5, 21 de diciembre de 1869, pág. 3, en Hemeroteca de la Biblioteca Pública de la Universidad Nacional de La Plata (en adelante, HBPUNLP). 
atraer y organizar votantes. En efecto, las fuentes localizadas revelan que los actores políticos intermedios fueron una pieza clave para la organización del entramado electoral, ya que el ejercicio de funciones en las esferas departamentales les permitió estrechar lazos con el vecindario de sus respectivas jurisdicciones y utilizar su posición como una herramienta clave para la movilización de las bases electorales.

Veamos rápidamente dos ejemplos. El primero es una carta firmada por un comandante del Séptimo Regimiento de Campaña, Benjamín de la Reta, un militar y político territorial del este de la provincia. En la carta, dirigida a un amigo, Reta habla de los trabajos electorales que está haciendo el club, organizado por el sector artesano: «En ese concepto y reconociendo su patriotismo no dudo que unirá sus esfuerzos a los nuestros para obtener en la próxima elección el triunfo de nuestras ideas sobre los que plegándose a la oposición no pueden causar sino males a nuestra provincia». ${ }^{8}$ A continuación, lo invita a una comida organizada para el día anterior a la elección de diputado.

Otros elementos del entramado relacional se localizan en las páginas de la prensa, en las que figuran solicitadas o comunicados publicados por los clubes electorales. Dichos anuncios estaban destinados, por lo general, a presentar las cualidades de sus candidatos y las listas de quienes se adherían a ellos. Estas últimas tenían como objetivo mostrar públicamente la cantidad de miembros que cada facción podía reclutar, así como a los «personajes distinguidos» que se vinculaban al club. Sin embargo, muchas veces, esas listas eran adulteradas. De acuerdo con la denuncia pública realizada por Ángel Godoy - un referente territorial del departamento de Junín que desempeñó numerosos cargos en esa jurisdicción entre 1869 y $1874-$, su nombre fue utilizado sin su consentimiento para apoyar las candidaturas del club opositor. ${ }^{9}$

La elección de diputados finalmente se practicó el 1 de enero de 1870 y triunfó la lista sostenida por el sector artesano. Esto le dio un gran impulso a este sector, que pocos días después anunció en la prensa que comenzarían a trabajar en las próximas elecciones de gobernador. A través de algunas solicitadas, se invitaba a todos los artesanos, ya fueran «jefes de taller» o «simples operarios», a una reunión con el objeto de decidir "por quién van a trabajar los artesanos». ${ }^{10}$ Luego de realizarse varios mítines en la ciudad de Mendoza, se pactó entre los artesanos que, ante la falta de unanimidad con respecto a quién sería el candidato al que apoyarían, «cada cual trabajaría por el que más le agrade». ${ }^{11}$ Una vez divididas las aguas, un grupo de artesanos optó por la candidatura de Arístides Villanueva, y otro, por la de Ezequiel García. De esta forma, surgieron los

8. «Votos electorales por un chanchito». La Opinión, Mendoza, año 1, núm. 9, 30 de diciembre de 1869, pág. 2, en HBPUNLP.

9. «Panorama». El Constitucional, Mendoza, año XIX, núm. 4.378, 1 de enero de 1870, pág. 3 , en Hemeroteca de la Biblioteca Pública General San Martín (en adelante, HBPGSM).

10. «A los artesanos de Mendoza». El Constitucional, Mendoza, año XIX, núm. 4389, 29 de enero de 1870, pág. 1, en HBPGSM.

11. «Ya es tiempo». El Constitucional, Mendoza, año xIX, núm. 4384, 18 de diciembre de 1870 , págs. 2-3, en HBPGSM. 
cimientos sobre los que se constituyeron los dos clubes electorales que se enfrentarían en la elección de gobernador de 1870.

La asociación que sostuvo la candidatura de Arístides Villanueva (18251900) - un político que había comenzado su trayectoria ocupando una banca en el Congreso Nacional como diputado por Mendoza entre 1862-1870 - fue el Club Electoral Independiente. La propaganda política desplegada por este club reivindicó la figura de Villanueva argumentando no solo sus cualidades personales, sino también su ascendencia familiar, vinculada con la independencia. Se resaltó, sobre todo, que Villanueva era miembro de una «antigua, conocida y honorable familia de esta sociedad». Su padre había sido parte de la «venerable lista de los padres de la patria» y luego había luchado por "conquistar y cimentar la independencia de la República» a través de su filiación al partido unitario y la Liga del Interior. ${ }^{12}$ Rubricaron el acta del club 369 socios. De ellos, el 58\% eran individuos que se habían suscripto por medio de las células instaladas por el club en los diferentes departamentos del interior provincial; mientras que el $42 \%$ restante correspondía a las suscripciones realizadas en la ciudad. El cuadro de apoyos de Villanueva se completaba con el periódico La Opinión y con el gobernador saliente, Nicolás A. Villanueva, que además era su primo.

El club rival fue el Club Constitucional, que sostuvo la candidatura de Ezequiel García (1809-¿?), un actor político provincial de reconocida trayectoria. Desde la década de 1850 había desempeñado funciones en la Cámara de Justicia y, luego, había sido elegido diputado provincial en reiteradas ocasiones (1862-1864; 1864-1866; 1868-1870) y convencional (en 1867). Su nombre se vinculaba a la tradición federal, cuyo referente era Urquiza, quien fue asesinado en abril de ese mismo año de 1870. A diferencia de su contrincante, el Club Constitucional no tenía un fuerte peso en el interior de la provincia, ya que, de los 269 afiliados, solo el 21,5\% se había suscrito a las células diseminadas en los departamentos alejados de la ciudad. García contó, además, con el apoyo del periódico El Artesano, editado especialmente entre julio y septiembre de 1870 con el fin de sostener su candidatura, y con el de El Constitucional. Este último, pese a ser el periódico oficial de la época y anunciar que mantendría una postura neutral en la contienda, adoptó una posición favorable hacia García y publicó duras críticas contra La Opinión y su candidato.

Tras varios meses de trabajos electorales desplegados por los dos clubes rivales en la ciudad y en las periferias de la provincia de Mendoza, la candidatura de Villanueva obtuvo el triunfo. En relación con esta investigación, nos interesa centrar nuestra atención en dos cuestiones: quiénes integraban los clubes conformados en 1870 y si es posible caracterizar sus perfiles sociales y ocupacionales.

12. Afiche de propaganda. «Arístides Villanueva. Candidato para gobernador». La Opinión, Mendoza, 26 de febrero de 1870, en HBPUNLP. 


\subsection{Composición de los clubes}

A los efectos de ensayar respuestas a los interrogantes planteados en el apartado anterior, se elaboró una base de datos que reúne información extraída de las actas de los clubes publicadas en la prensa, las células censales consultadas y los Registros Oficiales de la Provincia de Mendoza.

Una primera apreciación permite delinear la variedad de perfiles aglutinados en cada uno de los clubes, entre los que se distinguen dos tipos de socios: por un lado, los miembros que en 1870 ejercían cargos político-administrativos en la provincia y, por otro lado, aquellos personajes que no tuvieron ningún registro de notabilidad y que, por tanto, han sido muy difíciles de documentar. De acuerdo con la información recabada para esta investigación, el Club Electoral Independiente contó entre sus filas con $116(31,4 \%)$ miembros que estaban insertos en la vida política local; mientras que el Club Constitucional reclutó a 45 $(16,7 \%)$ socios que cumplían funciones públicas.

El análisis individual de las trayectorias de todos los individuos que ejercieron cargos políticos arroja algunos datos interesantes sobre la composición de ambos clubes. Dicho ejercicio permitió distinguir, por un lado, la siguiente jerarquía de socios: 1) dirigentes que rotaron por cargos tanto provinciales como departamentales; 2) autoridades departamentales intermedias y menores en la administración territorial; y 3) personajes con cargos de mando en las Guardias Nacionales. Por otro lado, posibilitó la identificación de algunas características o notas complementarias respecto a sus tradiciones e identidades políticas, así como las trayectorias asociativas de varios de ellos.

Analicemos en detenimiento el Club Electoral Independiente. Dicha asociación aglutinó en su interior a un grupo de distinguidos políticos que tuvieron un destacado recorrido político provincial y departamental, además de una activa participación en numerosos espacios de sociabilidad, sobre todo de tipo político. Entre ellos sobresalen: Francisco Civit, Daniel Videla Correa, Melitón Arroyo, Federico Corvalán y Carlos González.

Comencemos por Francisco Civit (1830-1908), quien forjó una dilatada trayectoria política provincial y nacional. Desde mediados de la década de 1850, Civit ejerció funciones en el poder ejecutivo provincial y, luego de Pavón, acompañó al gobernador Luis Molina como ministro de Hacienda interino y, posteriormente, como secretario de Gobierno. Sin embargo, se vio obligado a abandonar su cargo en el poder ejecutivo provincial tras resultar elegido para representar a la provincia en el Congreso Nacional (1862-1870), cuyo ejercicio se vio interrumpido tras ser designado ministro de Arroyo. Unos años más tarde, en 1873, Civit alcanzará la gobernación. ${ }^{13}$

13. Los datos sobre la trayectoria política de Civit han sido extraídos de los Registros Oficiales de la Provincia de Mendoza (Mendoza), en Archivo General de la Provincia de Mendoza (en adelante, AGPM), Sección Independiente. Años consultados: 1852-1890. 
Por su parte, Daniel Videla Correa tuvo una interesante carrera política que le permitió posicionarse como un referente territorial de Guaymallén y convertirse en un político reconocido en su provincia. Desde principios de la década de 1860, alternó el ejercicio de cargos legislativos y judiciales provinciales - defensor de pobres y menores, fiscal público, camarista interino, asesor de juzgado interino, juez del crimen y, en reiteradas ocasiones, como diputado provincial y elector de gobernador - con cargos departamentales intermedios y menores: fue subdelegado de Guaymallén entre 1865 y 1867 y, numerosas veces, formó parte de las mesas primarias y electorales en Guaymallén. En la década de 1870, durante los gobiernos de Arístides Villanueva y Francisco Civit, fue ministro de Gobierno. Asimismo, desde finales de la década de 1860 y a lo largo de 1870, tuvo una intensa participación en asociaciones culturales y educativas, tales como la Sociedad de los Amigos de la Infancia (1867), y políticas, como el Club Electoral Independiente (1870), el Club Liberal (1872-1878) y el Comité del Partido Liberal (1879), en las que muchas veces ocupó puestos directivos. ${ }^{14}$

Melitón Arroyo (1801-1875) fue un político local que desempeñó en diferentes oportunidades los cargos de diputado y elector de gobernador, al tiempo que participó en diversas comisiones y ocupó distintos puestos públicos: miembro de mesas primarias y electorales en Junín; jefe de la Policía de Ciudad; concejal (y presidente) de la Municipalidad de Ciudad. Además, ejerció la gobernación de Mendoza en 1866, pero fue depuesto por la Revolución de los Colorados $-y$, una vez restablecido, en abril de 1867, renunció a los pocos meses-. Asimismo, Arroyo tuvo una intensa injerencia en diferentes espacios de sociabilidad local: desde muy temprano participó en clubes electorales y fue miembro de la Sociedad Amigos de la Instrucción Popular (1870-1873). ${ }^{15}$

En cuanto a Federico Corvalán, tuvo una activa participación en la política local desde la década de 1850: diputado provincial $(1852,1853,1866)$, juez del crimen (1852), convencional (1854), juez de conciliación (1857), fiscal público (1866), miembro del Consejo de Gobierno de Arroyo (1867), secretario de Gobierno de Nicolás A. Villanueva (1867) y camarista suplente del Superior Tribunal de Justicia (1870), entre otros. Posteriormente, durante la década de 1870, alternó el ejercicio de cargos provinciales (fue secretario y asesor del Poder Ejecutivo provincial) y departamentales (concejal y presidente de la municipalidad de Ciudad) (Cutolo, 1971).

14. Datos extraídos de los Registros Oficiales de la Provincia de Mendoza (Mendoza), en AGPM, Sección Independiente. Años consultados: 1860-1880. Asimismo, se han consultado los siguientes artículos de periódicos: «Bibliotecas Populares. Prospecto». La Libertad, Mendoza, año 1, núm. 22, 20 de mayo de 1870, pág. 3, en HBPUNLP; «Acta». La Opinión, Mendoza, año 1, núm. 36, 19 de febrero de 1870, pág. 2; «Manifiesto del Partido Liberal», El Constitucional, Mendoza, año xxVIII, época Iv, núm. 1287, 6 de noviembre de 1879, pág. 1, en HBPGSM.

15. Los datos sobre la trayectoria de Arroyo fueron extraídos de los Registros Oficiales de la Provincia de Mendoza (Mendoza), en AGPM, Sección Independiente. Años consultados: 1840-1875; y de la prensa local: «Acta». La Opinión, Mendoza, año 1, núm. 36, 19 de febrero de 1870, pág. 2, en HBPUNLP; y «Manifiesto del Partido Liberal». El Constitucional, Mendoza, año xxVIII, época Iv, núm. 1287, 6 de noviembre de 1879, pág. 1, en HBPGSM. 
También se encuentra dentro de este grupo un distinguido empresario y político local, Carlos González, quien tuvo una intensa trayectoria pública tanto a través de algunos espacios de sociabilidad de la época (Club Electoral, en 1862, Club Libertad, en 1863, y Club Electoral Independiente, en 1870, entre otros) como por medio del ejercicio de diferentes cargos provinciales y departamentales. Desde finales de la década de 1850 resultó elegido diputado provincial en diversas oportunidades (1859, 1862-1864, 1869-1870); fue gobernador de Mendoza y, más tarde, miembro de los Consejos de Gobierno de Luis Molina (1862-1863) y Melitón Arroyo (1866 y 1867). Asimismo, ejerció cargos menores e intermedios: fue miembro de diversas comisiones organizadas por el Poder Ejecutivo; y en reiteradas oportunidades fue concejal de Ciudad y Las Heras. No obstante, en 1873 se apartó del grupo de los notables y aglutinó a su alrededor a los federales derrotados en 1867 y a los mitristas para enfrentarse en los comicios provinciales contra Francisco Civit, el candidato oficial (Bragoni, 1999).

Además de estos dirigentes que tuvieron una activa participación política luego de Pavón, el club contó entre sus filas con algunos personajes que habían protagonizado la revolución de 1866 y que, posteriormente, se integraron en el juego político. Por un lado, sobresale la figura de Saturnino P. de la Reta, un médico graduado en Chile que al regresar a la provincia fue designado por el Ejecutivo como médico de la Policía y el Hospital: y que, entre 1862 y 1866, ocupó una banca en la Legislatura provincial. Luego de su participación en la Revolución de los Colorados, se produjo una pausa en su actuación pública hasta 1870, año en el que se enroló en las filas del Club Electoral Independiente. Una vez que triunfó Villanueva en las elecciones de gobernador de 1870, Reta volvió a resultar elegido diputado provincial en dos oportunidades (1870-1872 y 1872-1873). ${ }^{16}$ Por otro lado, se distingue la trayectoria de Ramón Videla, un joven político que prácticamente comenzó su actuación pública con la revolución de 1866, en la que ejerció el cargo de diputado. No obstante, en 1868, luego de la derrota de los federales, Videla obtuvo una amnistía que le permitió retomar su actuación pública. Ese año fue nombrado jurado de imprenta, fue elegido concejal municipal en la Ciudad (18681869) y, en 1869, fue designado rector provisorio del Colegio Nacional, cargo que rechazó. Al año siguiente, Videla figuró como presidente del Club Electoral Independiente, lo que, probablemente, le posibilitó ampliar sus redes relacionales y desempeñar funciones en el ámbito provincial. En efecto, en 1870 fue elector de gobernador, diputado provincial y, posteriormente, ministro general interino y secretario de Gobierno interino en la gestión de Arístides Villanueva. Además, durante esos años tuvo una activa injerencia, como socio y como miembro directivo, en el Club Electoral Avellaneda (1873) y en el Club Liberal (1872-1873), levantados por la facción liberal, y también fue miembro del Comité Liberal (1879). ${ }^{17}$

16. Los datos sobre la trayectoria pública de Saturnino P. de la Reta han sido obtenidos en los Registros Oficiales de la Provincia de Mendoza, Mendoza, en AGPM, Sección Independiente. Años consultados: 1862-1866 y 1870-1873. También se han comprobado en las actas de los clubes mencionados publicados en la prensa.

17. Los datos sobre la trayectoria de Videla han sido extraídos de los Registros Oficiales de la Provincia de Mendoza, Mendoza, en AGPM, Sección Independiente. Años consultados: 1866-1873. 
En cuanto al Club Constitucional, la información recabada da cuenta de que, si bien este grupo aglutinó en su seno a algunos personajes destacados del escenario político provincial y departamental, su principal diferencia respecto al club adversario era que la mayoría de estas personalidades habían sido protagonistas de la Revolución de los Colorados. El hecho de que se encontraran entre los miembros del club varios de los antiguos rebeldes federales no es baladí, menos aún si se tiene en cuenta que los principales cargos del Comité Central, encargado de difundir la candidatura por los departamentos, estaban en sus manos.

El presidente de dicho comité fue Ezequiel Tabanera, un abogado (doctorado en Córdoba) y hacendado local, enrolado en las filas federales, que había actuado desde mediados de la década de 1850 en la Legislatura Provincial. Luego de Pavón, ejerció funciones de asesor en el poder judicial provincial, al tiempo que participó del levantamiento federal de 1863 y de la revolución de 1866. Tras conseguir la amnistía correspondiente, hacia finales de la década de 1860 volvió a integrar la Legislatura y comenzó a participar, de forma frecuente, en diversos espacios asociativos: el Club Constitucional (1870), la Sociedad Amigos de la Instrucción Popular (1870), el Club Electoral (1872), la Biblioteca Popular de la Ciudad (1872) y el Club Social (1874), entre otros. Asimismo, alternó el ejercicio de cargos provinciales con algunas funciones públicas en la municipalidad de Ciudad. ${ }^{18}$

Otro personaje fue Modesto Sánchez, vocal y secretario del comité. Sánchez se dedicaba al comercio e inició su actuación política a principios de la década de 1860 ocupando los cargos de juez del crimen (1861), diputado provincial (1861) y fiscal público (1863-1866). En 1866 se involucró en la Revolución de los Colorados, y una vez que esta fue derrotada se mantuvo fuera de la actividad política hasta 1870 , cuando fue elegido concejal del municipio de Ciudad e integró el comité directivo del Club Constitucional. Desde esa fecha hasta 1875, Sánchez participó continuamente en la vida política municipal de Ciudad. ${ }^{19}$

Signaba, además, la nómina del comité central Benito González Marcó, un empresario y político de dilatada trayectoria en el ámbito local que ejerció diversos cargos antes de involucrarse en la revolución de 1866. Desde los años cincuenta había cumplido funciones de: juez de conciliación (1852), miembro del Tribunal de Causas Criminales (1853), diputado provincial (1856-1858), miembro del Consejo de Gobierno de Moyano (1858), juez general de Aguas (1858, 1862, 1864), gobernador interino (marzo-abril de 1859), diputado provincial (1863-1864)

\footnotetext{
Asimismo, se ha consultado la prensa local: «Manifiesto del Partido Liberal». El Constitucional, Mendoza, año XXVIII, época IV, núm. 1287, 6 de noviembre de 1879, en HBPGSM.

18. Los datos sobre la trayectoria de Ezequiel Tabanera han sido consultados en los Registros Oficiales de la Provincia de Mendoza, Mendoza, en AGPM, Sección Independiente. Años consultados: $1854-1870$.

19. La trayectoria de Sánchez fue reconstruida a partir de la consulta de los Registros Oficiales de la Provincia de Mendoza, Mendoza, en AGPM, Sección Independiente. Años consultados: 18611875. Con respecto a su filiación al club Constitucional, véanse: «Solicitadas. Campo Libre». El Constitucional, Mendoza, año XIX, núm. 4444, 28 de enero de 1870, págs. 2-3, AGPM; y «Circular. Candidatura del ciudadano don Carlos Gonzáles». El Constitucional, Mendoza, año XXIII, núm. 301, 15 de abril de 1873, págs. 2-3, en AGPM.
} 
y subdelegado de Junín (1864). Paralelamente, mantuvo por esos años una activa injerencia en ámbitos asociativos como el prestigioso club político/social El Progreso (1857-1863). Y después de la derrota de los Colorados, volvió al escenario político en 1870, cuando se enroló en las filas del Club Constitucional y, más tarde, en otros clubes, entre ellos el Club Carlista (1873). ${ }^{20}$

Finalmente, adhirieron al Club Constitucional Manuel A. Sáez, vocal del comité, y Julio Lisandro Aguirre. Sáez fue un jurista de gran trayectoria política que, si bien no participó de manera activa en la revolución de 1866, realizó una petición de amnistía para los involucrados (Seghesso, 2007); mientras que Aguirre fue un político de dilatada trayectoria provincial y departamental. Este último, en 1866, al producirse la Revolución de los Colorados, se plegó al levantamiento y asumió el cargo de secretario de la Legislatura instalada por los revolucionarios; una vez vencidos los rebeldes, Aguirre obtuvo, en 1868, una amnistía, junto con los demás sediciosos. Un caso similar fue el de Lisandro Moyano, quien, en 1886, desempeñaba funciones de diputado suplente y se unió a los rebeldes colorados. Sus pasos por la política continuaron luego de obtener la correspondiente amnistía, que le permitió acceder dos años consecutivos al máximo cargo departamental, el de subdelegado, en Maipú. En esa localidad, Moyano, además, tuvo una activa injerencia asociativa: primero, en la difusión de la candidatura de García (1870) y, más tarde, en la de Carlos González para gobernador (1873) y en la de Alsina para presidente (1873). ${ }^{21}$

En cuanto a los socios de los clubes que fueron dirigentes departamentales, tales como subdelegados, comisarios, encargados de las mesas electorales, miembros de las municipalidades, jueces de paz, etc., la documentación analizada da cuenta de que cumplieron un rol vital en las jurisdicciones de campañas, ya que los dos clubes rivales organizaron una serie de comisiones encargadas de dirigir los trabajos electorales en los distintos departamentos. Las mismas estuvieron conformadas, en su mayoría, por funcionarios territoriales, por lo general provenientes de las clases subalternas que tuvieron un rol importante en sus respectivos distritos en el establecimiento de redes políticas, cuya importancia en el nivel municipal residía en su habilidad para reclutar y movilizar colectivamente votantes durante el proceso electoral.

De acuerdo con la información recabada, el Club Electoral Independiente contó entre sus filas con numerosas figuras departamentales encargadas de estas tareas. Asimismo, dentro del Club Electoral Independiente se distinguen dos comportamientos: por un lado, algunos hombres que, antes de 1870, habían tenido escasa actividad en la vida pública pero que, posteriormente, en la mayoría de los casos, lograron acceder a cargos de mayor jerarquía; ${ }^{22}$ y, por otro lado,

20. Respecto al itinerario de Benito González Marcó véase: Registros Oficiales de la Provincia de Mendoza (Mendoza), en AGPM, Sección Independiente. Años consultados: 1852-1870.

21. Respecto a los pasos por la política local de Aguirre y Moyano, véase: Registros Oficiales de la Provincia de Mendoza (Mendoza), en AGPM, Sección Independiente. Años consultados: 18601870.

22. Onofre Pelayes (Las Heras); Nicandro Barrionuevo (Maipú); Saturnino Zapata (Villeta); Casimiro Ibarzabal y Francisco Albino (Rosario); Regino Moyano y Marcelino Coria (Junín); Antonio Infan- 
hubo algunos actores que tuvieron una trayectoria política en sus respectivos distritos y que, a partir de 1870, continuaron ejerciendo el poder en el núcleo departamental, así como, en algunos casos, en el provincial, ya que a partir de ese año accedieron a cargos en la Legislatura o fueron designados por el gobernador para llevar a cabo funciones en la administración provincial. ${ }^{23}$

Respecto al Club Constitucional, el cotejo de datos indica que, a diferencia de su rival político, que aglutinó a un gran número de dirigentes territoriales en sus filas, este club solo contó con la adhesión de un subdelegado en ejercicio. Se trata de Ataúlfo Hoyos, quien fue designado subdelegado de Villeta, una jurisdicción creada en diciembre de 1869. No obstante, el Club Constitucional contó con un gran número de encargados de mesas electorales - en Ciudad y distintos departamentos - y de funcionarios de menor jerarquía. ${ }^{24}$ Asimismo, se distinguen dentro de este grupo algunas figuras de menor jerarquía que se involucraron en la revolución de 1866.

El tercer lugar de la jerarquía de socios en ambos clubes estuvo ocupado por actores con desempeño en las Guardias Nacionales. En ese sentido, numerosos estudios han señalado que los comandantes y otros jefes constituyeron puntos de articulación con la política, ya que muchas veces ellos mismos integraban los planteles de las dirigencias partidarias o, al menos, tenían estrechas conexiones con estas. Esta situación dio lugar a que se cometieran abusos por parte de los comandantes: el encarcelamiento de miembros de clubes opositores, la destitución de jefaturas opuestas y la presión ejercida sobre los jefes de la Guardia Nacional para trabajar por la candidatura oficial (Macías y Sabato, 2013).

Para el caso de las elecciones de 1870 solo se ha podido identificar a un núcleo pequeño de socios de ambos clubes que ese año estaban enrolados en las Guardias Nacionales.

En el Club Electoral Independiente figuraron treinta socios alistados en las Guardias. Dentro de este universo sobresalen, por un lado, algunos personajes que desempeñaron cargos intermedios y bajos vinculados a la tropa y que, además, tuvieron una destacada actividad en la vida política provincial. Entre ellos

te (Guaymallén); Ramón Quiroga (San Vicente); Florino Barreda (Ciudad); José Sosa, Proceso Moyano, Antonio Delgado, Federico Godoy, Apolinario Segundo Morán, Emilio Espínola, Eliseo Godoy y Juan Corvalán (San Martín); y Pastor Allende (Luján), entre otros.

23. Entre otros, se destacan: Blas Vargas, Agustín Aguirre, Pedro Nolasco Rosas y Agustín Reynals, quienes ejercieron una importante influencia en la zona de Luján; Demetrio Mayorga, posicionado en Ciudad, aunque asumió, también, la tarea de extender los trabajos electorales del club en San Rafael; José Albino Rodríguez, Víctor Urias Dubois y Julio Gutiérrez en Maipú; Cesáreo Estrella en San Vicente; Augusto Segovia, un comandante militar emplazado en San Rafael y San Carlos; José Silvestre Moyano, Ladislao Segura, Guillermo Segundo Cano y Pedro José Arenas, pertenecientes a Junín; Saturnino Reynals, quien logró desplegar su poder en los departamentos de San Martín y Junín; Manuel Olmedo y Gabriel Puebla en Guaymallén; Félix Lemos y Secundino Gómez en Tupungato; y Agustín Videla y Nicolás Godoy, quienes tuvieron una amplia movilidad entre los diversos departamentos de Mendoza en los que ejercieron cargos públicos.

24. Agustín Moreno (Ciudad); Manuel M. Martínez (Junín); Miguel Neira y Cesáreo Zapata (La Paz); Cirilo Torán y Joaquín Ortiz (Ciudad); Bazán Melchor y Serapio Pizarro (Rosario); José Cuitiño (San Martín); Juan de Dios Cejas (San Rafael); Francisco Estrella (San Vicente), y José Delgado (Tupungato), entre otros. 
destacan José Miguel Segura, Camilo Lemos, José Santos Biritos y César Palacios. Y, por otro lado, sobresalen también otros personajes que ejercieron mandos intermedios y bajos, y que no tuvieron ninguna trayectoria política más que su participación en el Club Electoral Independiente, aunque probablemente estuvieron ligados estrechamente con algunos dirigentes locales. Son los casos de Felipe Núñez (teniente segundo), Cruz Orosco (sargento segundo), Florencio Barrera (teniente segundo) y Jesús Ferreira (cabo segundo).

En cambio, en las filas del Club Constitucional figuraron solo siete socios enrolados en las Guardias Nacionales. A diferencia del club opositor, el Club Constitucional solo tuvo en sus filas a dos personajes con una mediana trayectoria militar y política: uno era Estratón Quintanilla, subteniente de Guardias Nacionales y, más tarde, ayudante mayor (1874), que entre 1869 y 1871 desempeñó cargos de recaudador fiscal (en Ciudad) y escrutador en las mesas electorales (también en Ciudad); y el otro era Faustino Sánchez, capitán de Guardias Nacionales, que en alguna ocasión estuvo a cargo de una mesa electoral en Ciudad. ${ }^{25}$

Finalmente, con respecto a los socios que constituyeron las bases de ambos clubes, se han reconstruido algunos perfiles sociales y ocupacionales a fin de descifrar algunos rasgos de este conglomerado. El 68,3\% de los socios del Club Electoral Independiente no tuvieron una actuación pública; mientras que en el Club Constitucional este porcentaje fue del $83,3 \%$, datos reveladores de la capacidad de los clubes y los dirigentes para movilizar adhesiones.

Los datos trabajados para el Club Electoral Independiente corresponden a 235 individuos, es decir, al 60\% de los socios que componían las bases de apoyo, los cuales pudieron ser identificados en las células censales. Mientras que el Club Constitucional contó con 223 socios que no tuvieron una participación pública reconocida, de los cuales se ha reunido información de 177 de ellos (el $79,3 \%)$.

Los perfiles de ambos clubes eran muy variados. Se puede distinguir que los socios del Club Electoral Independiente tienen mayor índice de alfabetización que los del Club Constitucional: en el primero, el $87,1 \%$ sabían leer y escribir, mientras que en el segundo solo el $52 \%$ de ellos sabía leer y escribir. Sin embargo, se desconoce el nivel de instrucción alcanzado por cada uno. Con respecto al lugar de procedencia de los socios, el Club Electoral Independiente estuvo conformado mayormente por argentinos, quienes representaban el 96,2\% del total de miembros, de los cuales el $88,1 \%$ era oriundo de Mendoza, y el resto, de otras provincias (Buenos Aires, San Juan, San Luis, Córdoba y Tucumán), mientras que el $3,8 \%$ restante era extranjero, mayormente de origen chileno. Por su parte, el Club Constitucional tuvo mayor participación de extranjeros en sus filas: el $9 \%$ no había nacido en Argentina, sino que procedían, en su mayor parte, de Chile, aunque también había algunos franceses e italianos.

Con relación a su actividad económica, los datos trabajados indican que los socios del Club Electoral Independiente realizaban diversas actividades econó-

25. Ambos itinerarios fueron reconstruidos a partir de la consulta de los Registros Oficiales de la Provincia de Mendoza, Mendoza, en AGPM, Sección Independiente. Años consultados: 1869-1874. 
micas: el 34,9\% de ellos eran trabajadores rurales; el 32,9\% eran hacendados y comerciantes; el 19,4\%, artesanos; el 1,1\%, presbíteros; el 0,7\% practicaban profesiones liberales (médicos o abogados), y el 8,3\% han sido agrupados en otras profesiones, entre las que se cuentan los servicios domésticos y los boticarios. Y sabemos de los socios del Club Constitucional que el 35,4\% eran trabajadores rurales; el 31,1\% eran artesanos; el 19,3\%, hacendados y comerciantes; el 6,9\% se dedicaban a profesiones liberales, y el 6,9\%, a otros oficios.

Es decir, que en términos comparativos se detecta un apoyo casi parejo de trabajadores rurales en ambos clubes, mientras que el sector de hacendados y comerciantes es más fuerte en el Club Electoral Independiente y el sector artesano es más fuerte en el Club Constitucional. Consideramos que estos datos reflejan en algún punto la recepción que tuvieron las propuestas políticas presentada por cada uno de los candidatos. Asimismo, es interesante anotar que la presencia del sector artesano en ambos clubes no fue un fenómeno particularmente mendocino, sino que guardó relación con casos provinciales (Navajas, 2009; Di Meglio, 2012, entre otros) e hispanoamericanos (Jaramillo Uribel, 1976; Romero, 1987; Sanin, 1998; Teitelbaum y Gutiérrez, 2008; Zalaquett Fuente-Alba, 2012, entre otros), que presentaron una coyuntura política favorable que permitió que las organizaciones de artesanos alcanzaran cierto protagonismo político. Si bien en cada lugar el fenómeno adquirió características propias, sus demandas fueron, por lo general, a favor del proteccionismo frente a la política librecambista que intentaba imponerse en varias regiones, al tiempo que organizaron una activa participación en las luchas políticas a través de los clubes electorales. Algo similar ocurrió en Mendoza, donde, según la evidencia reunida, la experiencia desarrollada buscó canalizar no solo reclamos gremiales, sino también la participación de grupos de artesanos y peones urbanos en la contienda política. Hacia 1864 estos sectores tuvieron visibilidad en la prensa local a partir de los reclamos al Gobierno provincial por las desventajas que tenían en relación con sus pares extranjeros residentes en la provincia, tales como el impuesto de patentes y el servicio en las Guardias Nacionales. ${ }^{26}$ Unos años después, en 1867, estos sectores conformaron el Club de Artesanos, que, además de objetivos de tipo gremial encauzados en la instalación de la Sociedad de Socorros Mutuos de Artesanos, realizaron, entre 1867 y 1869, trabajos electorales. Posteriormente, en 1870, cobraron un gran impulso con su participación en el Club Constitucional y la redacción de El Artesano.

De esta forma, el sector artesano local logró gravitar en las elecciones nacionales y provinciales que se llevaron a cabo en Mendoza. Tal como sucedió en otras provincias, la prensa exaltó la función social y política de este sector (Navajas, 2009) al presentarlo como un ejemplo de civismo y un elemento central en la vida de todo pueblo civilizado ya que su participación electoral «aseguraba la felicidad y bienestar de la nación». ${ }^{27}$

26. «Petición de los artesanos». El Constitucional, Mendoza, año XII, núm. 2.980, 27/2/1864, pág. 2 en HBPGSM.

27. «La Opinión». La Opinión, Mendoza, año 1, núm. 9, 30/12/1869, pág. 3 en HBPUNLP y «El Club Constitucional». El Constitucional, Mendoza, año XIX, núm. 4444, 28/1/1870, pág. 3 en AGPM. 
En rasgos generales, los trabajos electorales organizados por los artesanos buscaron sostener candidaturas que en cierto punto garantizaran su participación política y sus intereses sectoriales. Así, en las disputas electorales de 1870 la prensa local manifestó que, si bien en ambos clubes se dio una fuerte presencia del sector artesano, este tuvo más peso en el Club Constitucional, que postulaba:

\begin{abstract}
El pueblo de Mendoza cuyas instituciones han sido profundamente desquiciadas, primero por el terremoto de Marzo del 61, y después por su asoladora revolución del 9 de Noviembre, necesitan la mano reparadora que armonizando los intereses de todos en la órbita Constitucional, restablezca la confianza de los ciudadanos y dé al artesano laborioso, al afanoso labrador y al intrépido comerciante, todo terreno de seguridades, de que sus propiedades serán garantidas y que pueden entregarse con toda libertad al ejercicio de sus profesiones descansando tranquilos en que el primer magistrado de la Provincia velará para que no sean molestados ni interrumpidos en sus afanes con exigencias extraordinarias hijas solo del desquicio y el calor en que nos hallamos sumidos. ${ }^{28}$
\end{abstract}

Igualmente, la prensa destacaba que los principales cargos directivos del Club Constitucional recayeron entre miembros del cuerpo de artesanos. En ese sentido llaman la atención las figuras de Hipólito Lecont, presidente del Club Constitucional, y Epifanio García, vicepresidente. Este último fue un carpintero mendocino de dilatada trayectoria en el Club de Artesanos y en la Sociedad de Socorros Mutuos de Artesanos. Por su parte, Lecont fue un artesano de origen chileno que contrajo matrimonio con una mendocina perteneciente a los sectores populares y con la que tuvo descendencia. Al momento de contraer matrimonio, Lecont era propietario de una carpintería, que fue su capital inicial, tanto monetario como relacional, ya que la práctica de dicho oficio le permitió afiliarse como miembro de la Sociedad de Artesanos, de la mano de la cual tuvo sus primeras incursiones en la política local, dado que esta sociedad organizó la candidatura a la gobernación de Nicolás A. Villanueva en 1867. Hacia mediados de la década de 1860, Lecont adquirió un hotel, al que apodó Hotel Chile, que potenció su capital relacional, puesto que se convirtió en uno de los centros más frecuentados por las élites provinciales. Sus instalaciones no solo cumplían con la lógica función de alojar huéspedes, sino que también eran utilizadas para múltiples actividades sociales y políticas. En ellas, Lecont improvisó un teatro, por cuyos escenarios pasaron una gran variedad de artistas internacionales debido a la situación geográfica de la provincia, que la involucraba en el tráfico de bienes y servicios entre dos capitales: Santiago de Chile y Buenos Aires..$^{29}$ Además, sus salones fueron centro de atracción dominical de las élites mendocinas y chilenas que disfrutaban de su servicio de helados y asistían a tertulias, bailes y festejos patrios de ambas comunidades. Por último, el Hotel Chile sirvió como centro de reuniones políticas y fue

28. «El Club Constitucional». El Constitucional, Mendoza, año XIX, núm. 4444, 28/1/1870, pág. 3 en AGPM.

29. Al respecto conviene precisar que el Teatro 25 de Mayo había sido destruido por el terremoto (1861) y que la provincia había organizado comisiones encargadas de poner en marcha la construcción de uno nuevo. Con respecto a las compañías teatrales y musicales que actuaron en la provincia durante la segunda mitad del siglo XIX, véase: Sacchi de Ceriotto (2014). 
cuna de la fundación de sociedades y clubes, lo que permitió a Lecont vincularse con los sectores dirigentes locales. Esta situación probablemente contribuyó al desarrollo de su trayectoria pública. En efecto, hacia 1867 fue designado Comisario de la Ciudad, cargo que desempeñó solo unos meses, porque renunció, y luego fue nombrado comisario de la Policía, en 1868. Su activa participación en los asuntos políticos locales despertó fuertes críticas de sus adversarios, aunque esto no le impidió liderar el Club Constitucional en 1870.

\section{Palabras finales}

El análisis realizado a lo largo de estas páginas sobre elecciones practicadas en 1870 y el proceso electoral previo permite señalar algunas cuestiones interesantes que enriquecen el panorama general relativo a las prácticas electorales decimonónicas de Argentina.

Ciertamente, los políticos provinciales debían dirimir sus posiciones periódicamente, para lo cual utilizaban diversos recursos a los efectos de intervenir en el mercado de influencias y actualizar adhesiones personales. Ese modus operandi requería en cada elección poner en funcionamiento una maquinaria política capaz de asegurar la competencia. En ese sentido, los clubes electorales cumplieron un rol esencial en la puesta en marcha del juego electoral. Asimismo, de acuerdo con los resultados arrojados en esta investigación, podemos concluir que los clubes electorales fueron espacios propicios para que el entramado político local pudiera vincularse y hacer alianzas con el círculo de notables, las figuras políticas de segunda línea y las bases políticas, en pos de sostener candidaturas y también de proyectar o fortalecer sus propias trayectorias individuales.

A partir de la documentación examinada, ha sido posible trazar un panorama general de cada una de las piezas que conformaban ese ajedrez electoral en el que las jerarquías de dirigentes (provinciales, departamentales y con funciones de mando en Guardias Nacionales) resultaron claves para su articulación con las bases políticas. Estas últimas fueron engrosadas, en ambos clubes, con la participación activa de un buen número de artesanos y trabajadores urbanos y rurales. La localización de las nóminas de estos socios resultó de relevancia, ya que aportan evidencia notable sobre la participación de estos sectores en elecciones nacionales y provinciales, así como acerca del peso que tuvieron en la elección de candidatos y su posterior triunfo electoral. Tales bases sugieren, además, el papel desempeñado en la intermediación e integración política de grupos sociales urbanos del régimen político provincial decimonónico.

En ese sentido, la experiencia de la provincia de Mendoza permite advertir que el funcionamiento del sistema político - en vías de construcción - requirió la puesta en marcha de adhesiones y apoyos políticos con el fin de aceitar la maquinaria electoral. En efecto, a diferencia de lo que han sostenido algunos estudios previos, para el grupo político mendocino que detentó el poder durante la segunda mitad del siglo XIX no fueron suficientes los vínculos de parentesco, sino que debieron elaborar una densa trama de negociaciones con políticos 
locales y, en ocasiones, nacionales, así como con sectores de artesanos y trabajadores rurales, que requería ser reeditada periódicamente.

\section{Bibliografía}

BIRLE, Peter, et al. (ed.) (2007). Elites en América Latina. Madrid: Iberoamericana-Vervuert. BonAUDO, Marta (2003). «Las élites santafecinas entre el control y las garantías: el espacio de la Jefatura Política». En: SABATO, Hilda y LeTtIERI, Alberto (comps.). La vida política en la Argentina del siglo XIX. Armas, voces y votos. Buenos Aires: Fondo de Cultura Económica, págs. 259-276.

Bragoni, Beatriz (1999). Los hijos de la Revolución. Familia, negocios y poder en Mendoza en el siglo XIX. Buenos Aires: Taurus.

BRAGONI, Beatriz (2003). «Los avatares de la representación. Sufragio, política y elecciones en Mendoza, 1854-1881». En: SABATO, Hilda y LetTIERI, Alberto (comps.). La vida política en la Argentina del siglo XIX. Armas, votos y voces. Buenos Aires: Fondo de Cultura Económica, págs. 205-222.

CucchI, Laura (2014). «Reclutamiento y movilización electoral en la Argentina decimonónica. Experiencias políticas en la Ciudad y la campaña de Córdoba (1877-1880)». Revista Bicentenario, 13 (2), págs. 5-32.

Cutolo, Vicente O. (1971). Nuevo diccionario biográfico argentino (1750-1930). Buenos Aires: Elche.

Dı MEGLIO, Gabriel (2013). «La participación política popular en la provincia de Buenos Aires, 1820-1890. Un ensayo». En: FradkIN, Raúl y Dı MeglıO, Gabriel (comps.). Hacer política. La participación popular en el siglo XIX rioplatense. Buenos Aires: Prometeo, págs. 272-303.

GaLLo, Ezequiel (1986). «Argentina: society and politics, 1880-1916». En: BetHeLL, Leslie (ed.). The Cambridge history of Latin America. Vol. v. Cambridge: Cambridge University Press, págs. 359-392.

GonzÁlez BeRnaldo, Pilar (1999). «Los clubes electorales durante la secesión del Estado de Buenos Aires (1852-1861)». En: SABATO, Hilda (coord.). Ciudadanía política y formación de las naciones. México: Fondo de Cultura Económica, págs. 142-161.

HIRSCH, Leonardo (2017). La república proporcional de Buenos Aires (1890-1898). La consagración de los partidos políticos en la Argentina. Tesis doctoral. Universidad de Buenos Aires.

JARAmILlo URIBEL, Jaime (1976). «Las Sociedades Democráticas de Artesanos y la coyuntura política y social colombiana de 1848". Anuario Colombiano de Historia Social y de la Cultura, Bogotá, 8, págs. 5-18.

MAcíAs, Flavia y SABATO, Hilda (2013). «La Guardia Nacional: Estado, política y uso de la fuerza en la Argentina de la segunda mitad del siglo XIX». PolHis. Boletín Bibliográfico Electrónico del Programa Buenos Aires de Historia Política, Buenos Aires, 11, págs. 70-81.

Malamud, Carlos (ed.) (1995). Partidos políticos y elecciones en América Latina y la Península Ibérica, 1830-1930. Madrid: Instituto Universitario Ortega y Gasset.

NAVAJAS, María José (2009). «Los clubes políticos en Tucumán. Discursos, representaciones y prácticas». Estudios Sociales. Revista Universitaria Semestral, Santa Fe, 36, págs. 9-35. 
PALTI, Elías (2007). El tiempo de la política. El siglo xIx reconsiderado. Buenos Aires: Siglo XXI. Richard-Jorba, Rodolfo (1998). Poder, economía y espacio en Mendoza, 1850-1900. Del comercio ganadero a la agroindustria vitivinícola. Mendoza: Facultad de Filosofía y Letras - Universidad Nacional de Cuyo.

ROMERO, Luis Alberto (1987). "La Sociedad de la Igualdad: liberales y artesanos en la vida política de Santiago de Chile». Siglo XIX, 3, págs. 15-35.

SABATO, HILDA (1998). La política en las calles. Entre el voto y la movilización. Buenos Aires, 1862-1880. Buenos Aires: Sudamericana.

SABATO, HILDA (2014). «Los desafíos de la república. Notas sobre la política en la Argentina pos Caseros». Estudios Sociales, Revista Universitaria Semestral, Santa Fe, 46, págs. 77-117.

SABATo, Hilda y LeTtieRI, Alberto (coords.) (2003). La vida política en la Argentina del siglo XIX. Buenos Aires: Fondo de Cultura Económica.

SabATO, HiLda et al. (2011). Historia de las elecciones en la Argentina (1805-2011). Buenos Aires: El Ateneo.

SAcchi De Ceriotto, Antonieta (2014). La música, incansable viajera. Sesenta años de prácticas musicales en Mendoza: 1852-1812. Mendoza: EDIUNC.

SANIN, Francisco. (1998). "La literatura plebeya y el debate alrededor de la propiedad, Nueva Granada, 1849-1854». En: SABATO, Hilda (coord.). Ciudadanía política y formación de las naciones. Perspectivas históricas de América Latina. México: Fondo de Cultura Económica, págs. 181-202.

SEghesso, María Cristina (1988). «Historia del régimen electoral mendocino anterior a la ley Sáenz Peña (1853-1912)». Revista de Historia del Derecho, Buenos Aires, 16, págs. 471-472.

Seghesso, María Cristina (2007). El jurista Manuel Antonio Sáez (1834-1887). Voz crítica y pensamiento socio-jurídico sobre su tiempo. Mendoza: EDIUNC.

TeItelbaum, Vanesa y GutiéRREZ, Florencia (2008). «Sociedades de artesanos y poder público: Ciudad de México, segunda mitad del siglo XIX». Estudios de Historia Moderna y Contemporánea de México, Ciudad de México, 36, págs. 127-158.

ZaLAQUetT Fuente-Alba, Rodrigo (2012). «Los "clubs" políticos y su importancia en la socialización del pensamiento liberal en la revolución de 1859». Revista Alicanto, Copiapó, 5, págs. 6-12.

Fecha de recepción: 30 de mayo de 2021

Fecha de aceptación: 2 de septiembre de 2021

Fecha de publicación: 22 de diciembre de 2021 